\title{
The Relationship of Market-Oriented Culture, Internal-Market Orientation, Service Climate, and Customer-Oriented Service Behavior: Cross-Cultural Study of F\&B Industry in Taiwan, China, and the United States: An Abstract
}

\author{
Shun-Ching Horng and Ling-Hua Weng
}

\begin{abstract}
This study explores the relationship among market-oriented culture, internal market orientation, employee-perceived service climate, and employees' market-oriented behavior in the Food and Beverage industries in Taiwan, China, and the United States. We examined whether internal market orientation (IMO) would mediate the relationship between market-oriented culture (MOC) and employees' market-oriented behavior (MOB) and whether employee-perceived service climate (SC) would mediate the relationship between IMO and MOB. The results showed that IMO does mediate the relationship of MOC and MOB, while SC does not mediate the relationship of IMO and MOB. The individual difference in three regions was also examined. Furthermore, we were wondering if national differences play roles in the abovementioned mediation relationship; we explored moderation effect by using Hofstede's national dimensions, namely, power distance, uncertainty avoidance, individualism, masculinity, and long-term orientation. The individual differences in three regions were also examined. This is one of the few studies that bring together the related market orientation constructs with service industries in international context; this study will not only further verify the market orientation theory but also provide insights for service industries with cross border operation.
\end{abstract}

References Available Upon Request

This research is granted by the Ministry of Science and Technology, Taiwan (no. MOST 104-2410-H-004-165)

S.-C. Horng $\cdot$ L.-H. Weng $(\bowtie)$

National Chengchi University, Taipei, Taiwan

e-mail: schorng@nccu.edu.tw; 103355504@nccu.edu.tw 